IOS Press

\title{
Comparison of monomeric anthocyanins and colour stability of fresh, concentrate and freeze-dried encapsulated cherry juice stored at $38^{\circ} \mathrm{C}$
}

\author{
Virginia Sanchez, Rosa Baeza* and Jorge Chirife \\ Facultad de Ciencias Agrarias, Pontificia Universidad Católica Argentina (UCA), Cap. Gral. Ramón Freire 183, \\ Buenos Aires, Argentina
}

Submitted 8 July 2015; accepted 27 August 2015

\begin{abstract}
.
BACKGROUND: Anthocyanins are natural colorants and bioactive compounds widely distributed among vegetables and fruits. Unfortunately, in fruit juices stored at room temperature monomeric anthocyanins easily convert to colourless compounds and subsequently to insoluble brown pigments.

OBJECTIVE: The object of present study is to compare the stability of monomeric anthocyanins and colour changes during storage temperature at $38^{\circ} \mathrm{C}$ of pasteurized cherry juice, concentrate and freeze-dried juice.

METHODS: Colour changes of, pasteurized cherry juice $\left(18.7^{\circ} \mathrm{Brix}\right)$, concentrate $\left(61^{\circ} \mathrm{Brix}\right)$ and juice freeze-dried with addition of maltodextrin and arabic gum as encapsulating agents, were evaluated by CIELab parameters, $\mathrm{a}^{*}, \mathrm{~b}^{*}$ and, $\mathrm{L}^{*}$. Anthocyanins content was measured by $\mathrm{pH}$-differential method and total phenolics were determined by Folin-Ciocalteu method. The glass transition temperature $\left(\mathrm{T}_{\mathrm{g}}\right)$ of the freeze-dried matrix was determined.

RESULTS: It was found the stability of monomeric anthocyanins and colour retention during storage at $38^{\circ} \mathrm{C}$ was significantly superior in the freeze-dried encapsulated juice powder than in liquid cherry juices.

CONCLUSIONS: This is attributed to the protective encapsulation of the anthocyanins in the amorphous matrix of maltodextrin/arabic gum of reduced water activity.
\end{abstract}

Keywords: Anthocyanins, colour, stability, cherry juice, concentrate, freeze-dried, glass transition

\section{Introduction}

Anthocyanins are bioactive compounds present in many fruits, vegetables and their products. They are natural colorants widely distributed in fruit and vegetables; notably cherries and berries [1]. In addition, anthocyanins have multiple biological roles, e.g. antioxidant activity, anti-inflammatory action, inhibition of blood platelet aggregation and antimicrobial activity, and prevention of cholesterol-induced atherosclerosis [1,2].

Anthocyanins are the basis for the red, blue and purple colours of fruits, vegetables and their products. Unfortunately, under normal processing and storage at room temperature monomeric anthocyanins transform relatively easy to colourless compounds and subsequently to insoluble brown pigments [3]. Since anthocyanins impart a characteristic

*Corresponding author: Rosa Baeza, Facultad de Ciencias Agrarias, Pontificia Universidad Católica Argentina (UCA), Cap. Gral. Ramón Freire 183, (1426) Buenos Aires, Argentina. Tel./Fax: +54 114552 2711; E-mail: rosabaezabsas@yahoo.com.ar. 
colour to fruits and vegetables they have a considerable impact on consumer sensory acceptance due to perception of inferior product quality [1].

Several studies indicate anthocyanin stability is not merely a function of temperature but is also influenced by intrinsic properties of the product and process conditions. Patras et al. [4] reviewed some important aspects of anthocyanin degradation during thermal processing; conclusions regarding the mechanisms and kinetics of anthocyanin degradation during heat treatment were postulated.

Cherry juice is a good source of anthocyanins, but its stability during heat processing or accelerated storage temperature suffers from the same drawbacks as those from other fruit juices [5]. Arslan [6] studied the effects of degradation preventive agents on storage stability of anthocyanins in sour cherry concentrate. It was concluded the duration and temperature of storage influence anthocyanin stability in cherry juice.

The appearance of a food product is one of the most important quality characteristics for consumer acceptance. As for red fruit-based products such as cherry juice, attractive colour should remain relatively constant throughout shelf life [1]. However, as mentioned above colour stability of cherry juice stored at ambient temperature is a difficult task because of rapid anthocyanin degradation; even at refrigeration temperature of about $4^{\circ} \mathrm{C}[6]$.

The aim of this research was to study the stability of monomeric anthocyanins and color changes during $38^{\circ} \mathrm{C}$ storage of fresh $\left(18.7^{\circ} \mathrm{Brix}\right)$, concentrate $\left(61^{\circ} \mathrm{Brix}\right)$ and freeze-dried encapsulated pasteurized cherry juice, to determine the most satisfactory procedure to improve anthocyanin and red colour retention.Temperature of $38^{\circ} \mathrm{C}$ was selected because it is usually recommended for accelerated shelf life studies of foods to be marketed at ambient temperature [7].

\section{Materials and methods}

\subsection{Reagents}

Maltodextrin Dextrose Equivalent $10\left(\mathrm{MD}_{10}\right)$ from Productos de Maíz S.A., Buenos Aires, Argentina and Arabic Gum from Gelfix S.A., Buenos Aires, Argentina, were used for encapsulation of freeze dried cherry juice.

Ethanol and chlorhydric acid used as solvents for juice extraction were from Biopack, Buenos Aires, Argentina.

Folin-Ciocalteu reagent was purchased from Merck KgaA Darmstadt, Germany. Gallic acid used for phenolic standard curve was obtained from Anedra, Buenos Aires, Argentina.

\subsection{Samples}

Lapins Dark cherry fruit from Tunuyan, Mendoza (Argentina), was provided by Rio Alara S.A. The fruit was frozen at $-20^{\circ} \mathrm{C}$ until processing.

\subsubsection{Juice}

Frozen cherries were thawed in a water bath at $20^{\circ} \mathrm{C}$, blanched $\left(87^{\circ} \mathrm{C}, 3 \mathrm{~min}\right)$, destemmed and pitted, and processed in a blender with mesh to obtain the juice. Ascorbic $(0.25 \mathrm{~g} / \mathrm{kg})$ and citric $(4 \mathrm{~g} / \mathrm{kg})$ acids were then added; the juice was fractionated and sealed in hermetic plastic bags $50 \mathrm{~g}$ each, pasteurized $\left(90^{\circ} \mathrm{C}, 5 \mathrm{~min}\right)$, cooled and stored until used for the study.

\subsubsection{Concentrate}

A fraction of pasteurized juice described above $\left(18.7^{\circ}\right.$ Brix $)$ was evaporated at $40^{\circ} \mathrm{C}$ in vacuum at $25 \mathrm{mbar}$ in a Laborota Heidolf (Schwabach, Germany) rotary evaporator. The product obtained (61 ${ }^{\circ}$ Brix) was re-pasteurized, fractionated in sterile and hermetic flasks $10 \mathrm{~g}$ each and used for storage studies. This low temperature concentration did not alter anthocyanins content of juice.

\subsubsection{Freeze drying and encapsulation procedure}

Pasteurized cherry juice (18.7 ${ }^{\circ}$ Brix) was mixed with Maltodextrin $\mathrm{DE}_{10}$ and Arabic Gum (80:20) at a ratio of $25 \%$ of encapsulating agents, poured onto an aluminium tray and frozen at $-20^{\circ} \mathrm{C}$ during $24 \mathrm{~h}$. Then it was freeze 
dried at room temperature $\left(22 \pm 3^{\circ} \mathrm{C}\right)$ in a FIC-LI-I-E300-CRT freeze dryer (Buenos Aires, Argentina) operated with a freezing plate and condenser at $-40^{\circ} \mathrm{C}$ and a vacuum of $100 \mu \mathrm{m} \mathrm{Hg}$ during $40 \mathrm{~h}$. Freeze drying did not alter monomeric anthocyanin content of cherry juice. The freeze-dried amorphous carbohydrate microstructure was milled to obtain a powder which was fractionated in sterile, hermetic flasks $(5 \mathrm{~g})$ and stored.

\subsection{Storage conditions}

Samples were stored in darkness at $38^{\circ} \mathrm{C}$ for 33 days (fresh juice) and for 60 days (concentrate and freezedried); two samples of juice, concentrate and encapsulated freeze dried juice were removed at selected times to take measurements.

\subsection{Juice extract}

Five grams of juice were extracted twice in $20 \mathrm{ml}$ ethanol: $\mathrm{HCl} 0.1 \mathrm{~N}(85: 15)$. The pellets with no detectable residual content of phenolics, were eliminated by centrifugation and the supernatants were mixed and utilized for measurements of total phenolics, monomeric anthocyanins and colour. Samples of concentrate and freeze dried juice were previously reconstituted with water to their original weights.

\subsection{Methods}

\subsubsection{Physicochemical properties}

Total soluble solids content was evaluated with a manual refractometer Atago N2 (Tokyo, Japan). pH was measured at $25^{\circ} \mathrm{C}$ using a Hanna HI 8424 instrument (Hanna Instruments Inc., Woonsocket, RI, USA).

Water activity was determined using an electronic dew-point water activity meter Aqualab TE (Decagon Devices, Pullman, WA). The equipment was calibrated with saturated salt solutions in the water activity range of interest [8]. Moisture content was performed on $1.5 \mathrm{~g}$ of powder in an oven at $90^{\circ} \mathrm{C}$ up to constant weight.

Glass transition temperature $\left(\mathrm{T}_{\mathrm{g}}\right)$ of cherry juice freeze dried with maltodextrin + arabic gum was determined by differential scanning calorimetry (DSC) using a DSC822e 104 Mettler Toledo calorimeter (Schwerzenbach, Switzerland). The instrument was calibrated with indium $\left(156.6^{\circ} \mathrm{C}\right)$, lead $\left(327.5^{\circ} \mathrm{C}\right)$ and zinc $\left(419.6^{\circ} \mathrm{C}\right)$. Masurements were performed at a heating rate of $10^{\circ} \mathrm{C} / \mathrm{min}$. Hermetically sealed $40 \mu \mathrm{L}$ medium pressure pans were used, (an empty pan served as a reference). Thermograms were then evaluated using Mettler Stare program.

\subsubsection{Total phenolics}

Total phenolics (TP) were determined on the juice extract using the Folin-Ciocalteu method according to Waterhouse [9]. Sample absorbance at $765 \mathrm{~nm}$ (PG Instruments T60U UV-Vis spectrophotometer, Leicestershire, United Kingdom) was measured, and phenolic concentrations were expressed as gallic acid equivalent (GAE) in mg/100 g of product, calculated by means of a standard curve of gallic acid.

\subsubsection{Monomeric anthocyanin content}

Monomeric anthocyanin content of juice extracts was determined by pH differential method [10]. Absorbances were read at 510 and $700 \mathrm{~nm}$, and its content was calculated as cyanidin-3-glucoside in mg/100 g of product (MW: $449.2 \mathrm{~g} \mathrm{~mol}^{-1}$ and $\varepsilon: 26900 \mathrm{~L} \mathrm{~cm}^{-1} \mathrm{~mol}^{-1}$ ). Monomeric anthocyanin retention (\%) was relative to the initial content considered as $100 \%$.

\subsubsection{Colour measurements}

Cherry juice color was analyzed using a Minolta Spectrophotometer CM-600d (Konica Minolta Observer), with D65 illuminant and an observer angle of $2^{\circ}$. The colour measurement was obtained by placing $0.4 \mathrm{~g}$ of juice or reconstituted juice for concentrate and freeze dried samples, in plastic white containers. CIELab parameters (CIE $\left.1976 L^{*} a^{*} b^{*}\right)$ were $L^{*}$ for lightness, $a^{*}$ for redness and $b^{*}$ for yellowness. Calculations of $C^{*}\left(\left(a^{* 2}+b^{* 2}\right)^{1 / 2}\right)$ for chroma and $\mathrm{h}^{\circ}\left(\arctan \mathrm{b}^{*} / \mathrm{a}^{*}\right)$ for hue angle were made. Total colour difference was calculated as 
$\Delta \mathrm{E}^{*}=\left[\left(\Delta \mathrm{L}^{*}\right)^{2}+\left(\Delta \mathrm{a}^{*}\right)^{2}+\left(\Delta \mathrm{b}^{*}\right)^{2}\right]^{1 / 2}$ and expressed the magnitude of difference between 0 and 33 days of juice storage. The instrument was standardized with a white tile $\left(\mathrm{L}^{*}=91.10, \mathrm{a}^{*}=1.12\right.$ and $\left.\mathrm{b}^{*}=1.26\right)$.

\subsection{Data analysis}

Replicate bottles of each juice product were analyzed at indicated time of storage. All the parameters studied were determined at least by duplicate, and the average was reported. Colour parameters during storing were analyzed applying one-way ANOVA and Student-Newman-Keuls test for multiple means comparisons, using Infostat v.2009 (Universidad Nacional de Córdoba, Argentina). Pearson's correlations between colour parameter a* and monomeric anthocyanin content were made.

\section{Results and discussion}

Table 1 shows physicochemical characteristics of fresh $\left(18.7^{\circ} \mathrm{Brix}\right)$, concentrate $\left(61^{\circ} \mathrm{Brix}\right)$ and freeze-dried encapsulated cherry juice $\left(\mathrm{a}_{\mathrm{w}}=0.10\right.$ and $3.8 \pm 0.1 \%$ moisture content). Total phenolics and anthocyanin contents in fresh juice are within range reported in literature [11].

Figure 1 compares monomeric anthocyanin stability in the liquid juices (fresh and $61^{\circ}$ Brix concentrate) and in the encapsulated cherry juice powder during storage at $38^{\circ} \mathrm{C}$. It can be seen that in fresh and concentrate juices anthocyanin retention decreases rapidly during storage while in the freeze dried powder is much more stable. At 33 days of storage the $\%$ anthocyanin retention in the liquid juices (both fresh and concentrate) fell to $11 \%$ while it remained at around $90 \%$ in the powder.

The poor stability of anthocyanins in the liquid juices stored at $38^{\circ} \mathrm{C}$ is in agreement with literature data, as reviewed in Table 2 which shows the half-life of monomeric anthocyanin degradation $\left(t_{1 / 2}=\right.$ time to reduce concentration to $50 \%$ of its initial value) in various fruit juices (mainly berries) stored at near $38^{\circ} \mathrm{C}$. Half-life times ranged between 2.1 days to 31.5 days highlighting the limited stability of monomeric anthocyanins [12-20].

Table 1

Physico-chemical characteristics of cherry juices used in this study

\begin{tabular}{lccccc}
\hline & $\begin{array}{c}\text { Total soluble } \\
\text { solids }\left({ }^{\circ} \text { Brix }\right)\end{array}$ & $\mathrm{pH}$ & $\mathrm{a}_{\mathrm{w}}$ & $\begin{array}{c}\text { Total phenolics } \\
\text { content }(\mathrm{mg} / 100 \mathrm{~g})\end{array}$ & $\begin{array}{c}\text { Monomeric anthocyanins } \\
(\mathrm{mg} / 100 \mathrm{~g})\end{array}$ \\
\hline Fresh juice & $18.7 \pm 0.1$ & $3.71 \pm 0.01$ & $0.973 \pm 0.001$ & $159 \pm 11$ & $23.5 \pm 0.2$ \\
Juice Concentrate & $61.0 \pm 0.1$ & $3.90 \pm 0.01$ & $0.824 \pm 0.001$ & $459 \pm 20$ & $86.2 \pm 2.9$ \\
Freeze-dried encapsulated juice & & & $0.100 \pm 0.001$ & $392 \pm 30$ & $67.5 \pm 4.0$ \\
\hline
\end{tabular}

Values are means \pm standard errors.



Fig. 1. Comparison of monomeric anthocyanins retention in: $\Delta$ freeze dried encapsulated $\left(\mathrm{a}_{\mathrm{w}}=0.10\right), \diamond$ concentrate $\left(61{ }^{\circ} \mathrm{Brix}\right)$ and $\circ$ fresh $(18.7$ ${ }^{\circ}$ Brix) cherry juices stored at $38^{\circ} \mathrm{C}$. 
Table 2

Half-life of monomeric anthocyanin degradation $\left(\mathrm{t}_{1 / 2}\right)$ in various (fresh and concentrate) fruit juices (mostly berries) stored at near $38^{\circ} \mathrm{C}$

\begin{tabular}{|c|c|c|c|c|c|c|}
\hline Fruit juice & ${ }^{\circ}$ Brix & $\mathrm{pH}$ & $\begin{array}{c}\text { Storage } \\
\text { Temperature }\left({ }^{\circ} \mathrm{C}\right)\end{array}$ & $\begin{array}{l}\text { Previous thermal } \\
\text { treatment }\end{array}$ & $\mathrm{t} 1 / 2$ (days) & Reference \\
\hline Elderberry & 36.8 & 3.6 & 40 & Pasteurized at $80^{\circ} \mathrm{C}$ & 27.7 & Busso Casati et al., 2015 \\
\hline Pomegranate & 13.7 & 3.2 & 37 & Pasteurized at $93^{\circ} \mathrm{C}$ & 25.4 & Alighourchi et al, 2009 \\
\hline Bloor orange & 45 & 3.4 & 37 & $\begin{array}{l}\text { Concentrated at } 80^{\circ} \mathrm{C} \\
\text { in Rotavapor }\end{array}$ & 2.1 & Kirca et al., 2003 \\
\hline Bloor orange & 69 & 3.4 & 37 & $\begin{array}{l}\text { Concentrated at } 80^{\circ} \mathrm{C} \\
\text { in Rotavapor }\end{array}$ & 3.1 & Kirca et al., 2003 \\
\hline $\begin{array}{l}\text { Black carrot in } \\
\text { various juices }\end{array}$ & 9.9-26.2 & $3.0-3.9$ & 37 & Pasteurized at $85^{\circ} \mathrm{C}$ & $12-16$ & Kirca et al., 2006 \\
\hline Black carrot & 30 & 4.3 & 37 & Pasteurized at $85^{\circ} \mathrm{C}$ & 28.7 & Kirca et al., 2007 \\
\hline Black carrot & 45 & 4.3 & 37 & Pasteurized at $85^{\circ} \mathrm{C}$ & 31.5 & Kirca et al., 2007 \\
\hline Black carrot & 64 & 4.3 & 37 & Pasteurized at $85^{\circ} \mathrm{C}$ & 28 & Kirca et al., 2007 \\
\hline Blackberry & 8.9 & 2.9 & 37 & Pasteurized at $85^{\circ} \mathrm{C}$ & 11.7 & Wang and $\mathrm{Xu}, 2007$ \\
\hline Blackberry & 65 & 2.9 & 37 & Pasteurized at $85^{\circ} \mathrm{C}$ & 9.4 & Wang and $\mathrm{Xu}, 2007$ \\
\hline Sour cherry & 45 & 3.2 & 37 & Pasteurized & 14 & Cemeroglu et al., 1994 \\
\hline Sour cherry & 71 & 3.1 & 37 & Pasteurized & 11 & Cemeroglu et al., 1994 \\
\hline $\begin{array}{l}\text { Agraz (Vaccinium } \\
\text { meridionale sw) }\end{array}$ & 2.5 & 3 & 37 & Pasteurized at $85^{\circ} \mathrm{C}$ & 4.9 & Martínez Zambrano et al., 2011 \\
\hline $\begin{array}{l}\text { Agraz (Vaccinium } \\
\text { meridionale sw.) }\end{array}$ & 19.5 & 2.6 & 37 & Pasteurized at $85^{\circ} \mathrm{C}$ & 21 & Martínez Zambrano et al., 2011 \\
\hline Model blackcurrant juice & 11 & 3.4 & 40 & $\begin{array}{l}\text { Fruits blanched in } \\
\text { boiling water } 2 \mathrm{~min}\end{array}$ & 9.4 & Harbourne et al., 2008 \\
\hline
\end{tabular}

Cherry juice was encapsulated by freeze drying with a mixture of encapsulating agents (maltodextrin and arabic gum) to protect anthocyanins in an amorphous glassy matrix [21, 22]. Cherry juice has a high monosaccharides content; main sugars are fructose and glucose (with small amounts of sucrose). It is well known these sugars (mainly fructose) have very low glass transition temperatures, $\mathrm{T}_{\mathrm{g}}[23]$. Thus, one may expect structural collapse in the amorphous structure if cherry juice is attempted to freeze dried alone. For this reason encapsulating agents (maltodextrin and arabic gum) were used to increase the resulting glass transition temperature; thus improving its physical properties [24].

Figure 2 shows the DSC thermogram for encapsulated cherry juice at a water activity of 0.10 ; the onset, midpoint and endpoint glass transition temperature values are indicated. Although a glass transition seems to be apparent in the thermogram, the witdth of the glass transition (difference between the end and onset values) is large (over $20^{\circ} \mathrm{C}$ ) suggesting that in this case $\mathrm{T}_{\mathrm{g}}$ is actually a transition region, rather than a specific temperature. Since the convention is to report a single temperature, the midpoint glass transition temperature $\left(35.5^{\circ} \mathrm{C}\right)$ was taken as most representative of the thermal transition in freeze-dried encapsulated cherry juice [25]. Since the midpoint glass transition temperature $\left(35.5^{\circ} \mathrm{C}\right)$ is close to the storage temperature $\left(38^{\circ} \mathrm{C}\right)$ one may explain the stability of anthocyanins (Fig. 1) due to the existence of a cuasi glassy state. It is known that physical changes in an amorphous matrix are time dependent being a function of ( $\mathrm{T}-\mathrm{Tg})$, where $\mathrm{T}$ is the storage temperature. In present conditions this difference $\left(38-35.5^{\circ} \mathrm{C}\right)$ is very small and the system would behave as in the glassy state, at least for the time-scale of present work (60 days) [24]. As observed in Fig. 3 visual examination of the dry cherry powder after 60 days storage at $38^{\circ} \mathrm{C}$ revealed absence of collapse/caking therefore confirming a glassy-like behavior.

Laine et al. [26] reported that a polyphenol-rich raspberry extract was stabilized by freeze-drying with maltodextrins as material coating, and found the freeze-dried particles were stable over long periods providing to polyphenols an effective protection against the oxidation phenomenon during their storage. Estupiñan et al. [27] found that addition of maltodextrin $\mathrm{DE}_{20}$ improved the color and stability of antioxidants in freeze-dried powders from Andes berry 


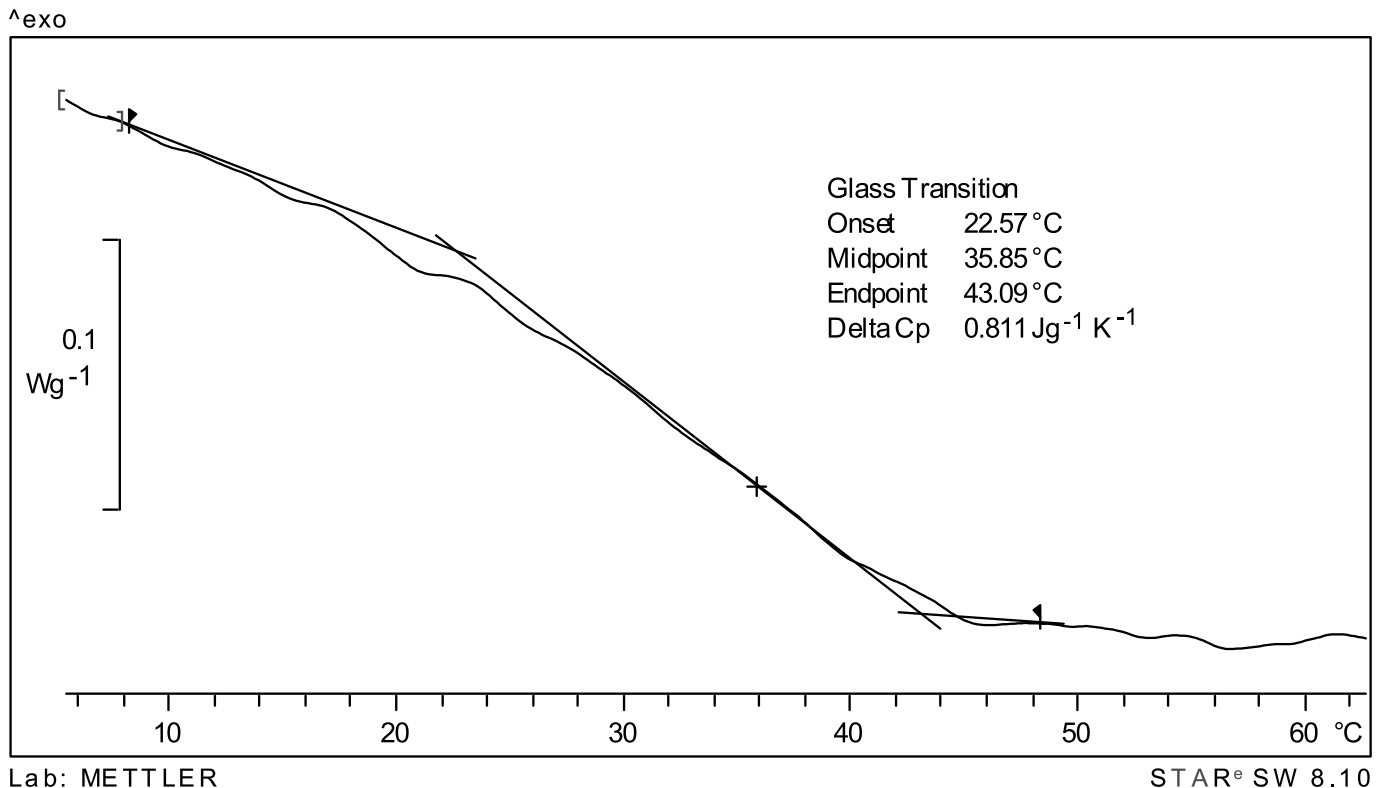

Fig. 2. DSC thermogram for cherry juice freeze-dried encapsulated in a maltodextrin/arabic gum matrix of $a_{w}=0.10$.

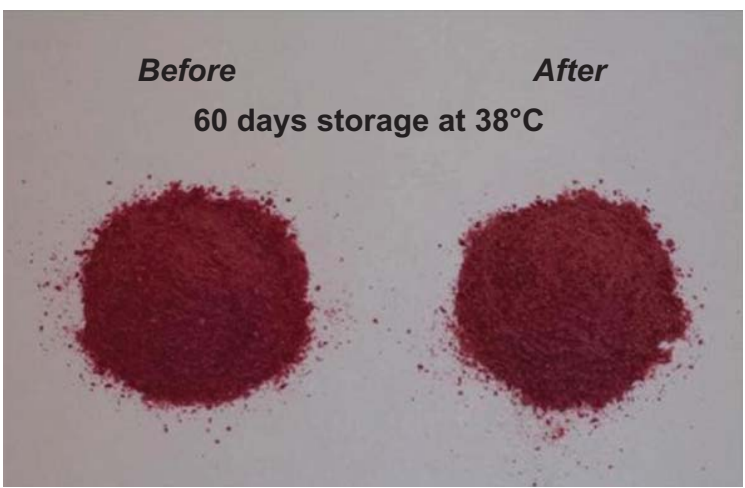

Fig. 3. Encapsulated cherry juice powder $\left(\mathrm{a}_{\mathrm{w}}=0.10\right)$ before and after 60 days storage at $38^{\circ} \mathrm{C}$ - left side : before storage; right side : after storage.

during storage. Osorio et al. [28] also reported that the stability of anthocyanins was enhanced by spray drying encapsulation in maltodextrin and/or arabic gum matrixes.

The attractive red colour of cherry juice plays such a vital role in consumer sensory acceptance; therefore, it is highly desirable it should remain relatively constant throughout shelf life. Figure 4 shows colour parameter $a^{*}$ (redness) as a function of storage time for liquid juices (fresh and concentrate) and encapsulated juice of low water activity. It can be seen that parameter $\mathrm{a}^{*}$ decreases rapidly from the beginning of storage for both liquid cherry juices but remained more or less constant for the encapsulated cherry juice. These results resemble those showed in previous Fig. 2, which compared the monomeric anthocyanin stability of liquid juices (regular and $61^{\circ}$ Brix concentrate) and encapsulated juice, suggesting that the loss of anthocyanins is associated to loss of characteristic red colour. For fresh and concentrate juices a high correlation between parameter $\mathrm{a}^{*}$ and anthocyanin content during storage was found, being $R=0.94$ and 0.95 respectively $(P<0.05)$.

Figure 5 shows the changes in all colour parameters: $a^{*}$ (redness), $b^{*}$ (yellowness), L* (lightness), as well as calculated purity $\left(\mathrm{C}^{*}\right)$ and hue angle $\left(\mathrm{h}^{\circ}\right)$ values, for liquid juices and encapsulated juice before and after 33 days 


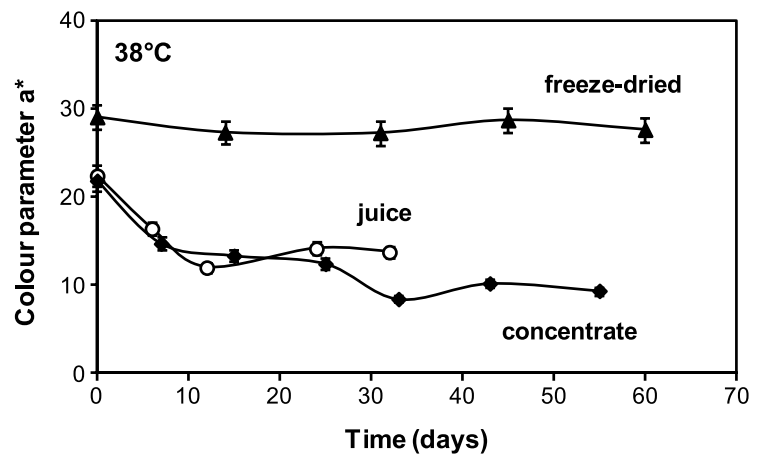

Fig. 4. Comparison of $\mathrm{a}^{*}$ (redness) colour parameter of: $\boldsymbol{\Delta}$ freeze dried encapsulated $\left(\mathrm{a}_{\mathrm{w}}=0.10\right), \diamond$ concentrate $\left(61{ }^{\circ} \mathrm{Brix}\right)$ and $\circ$ fresh $\left(18.7^{\circ}\right.$ Brix) cherry juices stored at $38^{\circ} \mathrm{C}$.
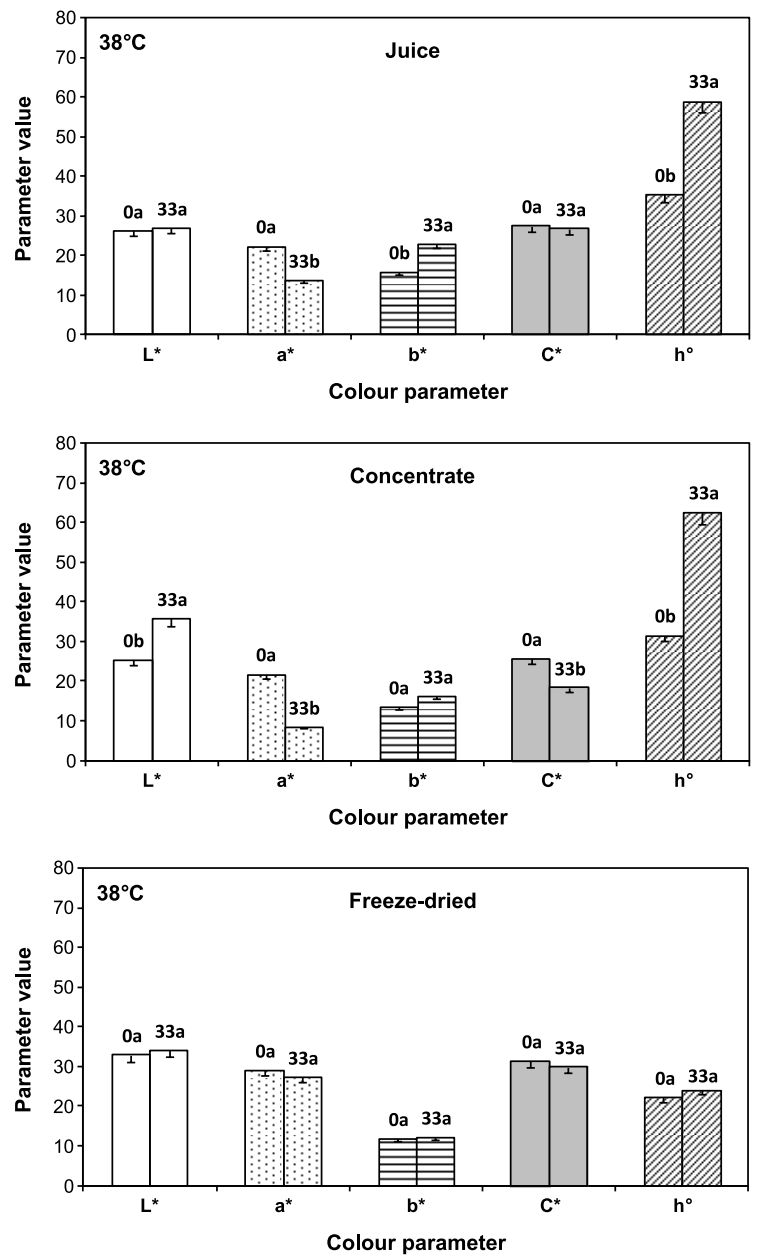

Fig. 5. Comparison of all colour parameters $\left(\mathrm{L}^{*}, \mathrm{a}^{*}, \mathrm{~b}^{*}, \mathrm{C}^{*}, \mathrm{~h}^{\circ}\right)$ in freeze dried encapsulated, concentrate $\left(61^{\circ} \mathrm{Bx}\right)$ and fresh $\left(18.7^{\circ} \mathrm{Bx}\right)$ cherry juice at 0 and 33 days stored at $38^{\circ} \mathrm{C}$. Different letters above the data bars indicate that colour parameter differed between storage time, $P<0.05$, Student-Newman-Keuls test. 
storage at $38^{\circ} \mathrm{C}$. Overall, it can be observed that colour parameters experimented significant modifications in the liquid juices (18.7 and $61^{\circ}$ Brix) after 33 days at $38^{\circ} \mathrm{C}$, with decreased $\mathrm{a}^{*}$ and increased $\mathrm{b}^{*}$ resulting in a higher tone $\left(\mathrm{h}^{\circ}\right)$ value and in a brownish juice. For the encapsulated juice the changes were much less important. Total colour difference $\left(\Delta \mathrm{E}^{*}\right)$ values were $11.2 \pm 0.1,18.6 \pm 0.5$ and $2.2 \pm 0.3$ for fresh, concentrate and freeze dried juice respectively, indicating more noticeable visual changes in colour during storage in liquid systems; these changes being more relevant for concentrate juice. Particularly in this case significant increase of lightness $\left(\mathrm{L}^{*}\right)$ and decline of saturation $\left(\mathrm{C}^{*}\right)$ were observed; and this may be attributed to non-enzymatic browning reactions which are known to proceed faster at intermediate water activity [29]. Changes in $\mathrm{L}^{*}$ and $\mathrm{C}^{*}$ values produce fading of colour that could reflect decolourization of anthocyanins and a shift from vivid to a duller colour respectively. Similar results were obtained in strawberry puree storing 8 weeks at $25^{\circ} \mathrm{C}$ as a consequence of processing and storage [30].

\section{Conclusions}

In addition to contributing to bioactive properties, attractive colour is one of the most important sensory characteristics of cherry juice. However, in pasteurized liquid juices (fresh and concentrate) both anthocyanin content and red colour are unstable and susceptible to degradation during storage at $38^{\circ} \mathrm{C}$. On the contrary, the encapsulated cherry juice powder of low water activity, exhibited a good stability of both anthocyanins and colour parameters.

Maintaining anthocyanin content as well as a stable red colour in cherry juice during storage at room temperature is problematic; thus juice encapsulation in a dried matrix of low water activity could be used as a strategy for product stabilization.

\section{Acknowledgments}

Authors acknowledge to Rio Alara S.A (Buenos Aires, Argentina) for donating the cherry fruits.

\section{References}

[1] Busso Casati C, Sanchez V, Baeza R, Magnani N, Evelson P, Zamora MC. Relationships between colour parameters, phenolic content and sensory changes of processed blueberry, elderberry and blackcurrant commercial juices. International Journal of Food Science and Technology. 2012;47(8):1728.

[2] Mazza G, Miniati E. Anthocyanins in fruits, vegetables, and grains. Mazza G, Miniati E,. Boca Raton, CRC Press 1993.

[3] Markakis P. Stability of Anthocyanins in Foods. In: Markakis, P. editor. Anthocyanins As Food Colors. New York: Academic Press; 1982, pp. 163.

[4] Patras A, Brunton NP, O’Donnell C, Tiwari BK. Effect of thermal processing on anthocyanin stability in foods; mechanisms and kineticsof degradation. Review. Trends in Food Science \& Technology. 2010;21(1):3.

[5] Kelebek H, Selli S. Evaluation of chemical constituents and antioxidant activity of sweet cherry (Prunus avium L.) cultivars. International Journal of Food Science \& Technology. 2011;46(12):2530.

[6] Arslan D. Effects of degradation preventive agents on storage stability of anthocyanins in sour cherry concentrate. Agronomy Research. 2015;13(4):892.

[7] Labuza TP, Schmidl MK. Accelerated shelf life testing of foods. Food Technology. 1985;39(9):57.

[8] Favetto GJ, Resnik SL, Chirife, J, Ferro Fontá C. Statistical evaluation of water activity measurements obtained with the Vaisala Humicap humidity meter. Journal of Food Science. 1983;487(2):534.

[9] Waterhouse AL. Determination of total phenolics. In: Wrolstad RE, editor. Current Protocols in Food Analytical Chemistry. New York: Wiley \& Sons; 2001, pp. I1.1.1.

[10] Giusti MM, Wrolstad RE. Characterization and measurement of anthocyanins by UV-visible spectroscopy. In: Wrolstad R, Acree T, An H, Decker E, Penner M, Reis D, Schawrtz S, Shoemaker C, Spoms P, editors. Current Protocols in Food Analytical Chemistry (1st.edn). New York: John Wiley and Sons, Inc.; 2001, pp F1.2.1.

[11] Kelley DS, Rasooly R, Jacob RA, Kader AA, Mackey BE. Consumption of Bing sweet cherries lowers circulating concentrations of inflammation markers in healthy men and women. J Nutr. 2006;136(4):981.

[12] Busso Casati C, Baeza R, Sanchez V, Catalano A, López P, Zamora MC. Thermal degradation kinetics of monomeric anthocyanins, colour changes and storage, effect in elderberry juices. Journal of Berry Research. 2015;5(1):29. 
[13] Alighourchi H, Barzegar M. Some physicochemical characteristics and degradation kinetic of anthocyanin of reconstituted pomegranate juice during storage. Journal of Food Engineering. 2009;90(2):179.

[14] Kirca A, Cemeroğlu B. Degradation kinetics of anthocyanins in blood orange juice and concentrate. Food Chemistry. 2003;81(4):583.

[15] Kirca A, Őzkan M, Cemeroğlu B. Stability of black carrot anthocyanins in various fruit juices and nectars. Food Chemistry. 2006;97(4):598.

[16] Kirca A, Őzkan M, Cemeroğlu B. Effects of temperature solid content and pH on stability of black carrot anthocyanins. Food Chemistry. 2007;101(1):212

[17] Wang WD, Xu SY. Degradation kinetics of anthocyanins in blackberry juice and concentrate. Journal of Food Engineering. $2007 ; 82$ (3):271.

[18] Cemeroğlu B, Velioğlu S. Degradation kinetics of anthocyanins in sour cherry juice and concentrate. Journal of Food Science. 1994;59(6):1216.

[19] Martínez Zambrano J, Rojas Sarmiento H, Borda Guerra G, Hastamorir Caro, A, Medina Rianño M. Estabilidad de antocianinas en jugo y concentrado de agraz (Vaccinium Meridionalle Sw.). Revista Facultad Nacional de Agronomía - Medellín. 2011;64(1):6015.

[20] Harbourne M, Jacquier JC, Morgan D, Lyng J. Determination of the degradation kinetics of anthocyanins in a model juice system using isothermal and non-isothermal methods. Food Chemistry. 2008;111(1):204.

[21] Galmarini M, Maury C, Mehinagic E, Sanchez V, Baeza R, Mignot S, Zamora MC, Chirife J. Stability of individual phenolic compounds and antioxidant activity during storage of a red wine powder. Food and Bioprocess Technology. 2013;6(12):3585.

[22] Sanchez V, Baeza R, Galmarini M, Zamora MC, Chirife J. Freeze-drying encapsulation of red wine polyphenols in an amorphous matrix of maltodextrin. Food and Bioprocess Technology. 2013;6(5):1350.

[23] Roos Y. Phase Transitions in Foods. NY, USA: Academic Press; 1995.

[24] Roos Y, Karel M. Phase transition of mixtures of amorphous polysaccharides and sugars. Biotechnology Progress. 1991;7(1):49.

[25] Cherian G, Chinachoti P. $2 \mathrm{H}$ and 170 Nuclear magnetic resonance study of water in gluten in the glassy and rubbery state. Cereal Chem. 1996;73(5):618.

[26] Laine P, Kylli P, Heinonen M, Jouppila K. Storage stability of microencapsulated cloudberry (Rubus chamaemorus) phenolics. Journal of Agriculture and Food Chemistry. 2008;56(23):11251.

[27] Estupiñan DC, Schwartz SJ, Garzón GA. Antioxidant activity, total phenolics content, anthocyanin, and color stability of isotonic model beverages colored with Andes berry (Rubus glaucus Benth) anthocyanin powder. Journal of Food Science. 2011;76(1):S26.

[28] Osorio C, Acevedo B, Hillebrand S, Carriazo J, Winterhalter P, Morales AL. Microencapsulation by spray-drying of anthocyanin pigments from Corozo (Bactris guineensis) fruit. Journal of Agricultural and Food Chemistry. 2010;58(11):6977.

[29] Labuza TP, Warren RM, Warmbier HC. The physical aspects with respect to water and non-enzymatic browning. Adv Exp Med Biol. 1977;86(B):379.

[30] Howard LR, Brownmiller C, Prior RL. Improved color and anthocyanin retention in strawberry puree by oxygen exclusion. Journal of Berry Research. 2014;4(2):107. 